\title{
Inquiry-Based Learning in Public Health/Health Sciences
}

\section{Kati Mozygemba, Ulrike Lahn, Tobias Bernhardt, and Anne Dehlfing}

Public health sciences is still a relatively recent field of study at German universities and universities of applied sciences; it encompasses efforts to prevent disease, extend life and promote health (DGPH 2015), thus clearly pursuing a political mandate. In the present text, we will first characterize public health/health sciences on the basis of four characteristic features. We will ask about their relevancy to teaching in the field and, in particular, for implementing inquiry-based learning; we present examples of the implementation of inquiry-based learning in the health sciences, and, finally, reflect on these in a critical light.

\footnotetext{
K. Mozygemba, Dr. (ه)

Universität Bremen, Fachbereich Human- und Gesundheitswissenschaften, Institut für Public Health und Pflegeforschung, Abteilung Versorgungsforschung, Bremen, Germany e-mail: kati.mozygemba@uni-bremen.de

U. Lahn, Dipl. Soz.

Fachhochschule Dortmund, Fachbereich Angewandte Sozialwissenschaften,

Dortmund, Germany

e-mail: ulrike.lahn@fh-dortmund.de
}

T. Bernhardt, MA

Jade Hochschule, Fachbereich Bauwesen Geoinformation Gesundheitstechnologie,

Wilhelmshaven, Germany

e-mail: tobias.bernhardt@jade-hs.de

\section{A. Dehlfing, MA PH}

Universität Bremen, Fachbereich Human- und Gesundheitswissenschaften, Institut für Public Health und Pflegeforschung, Abteilung Versorgungsforschung, Bremen, Germany

e-mail: anne.dehlfing@uni-bremen.de 


\subsection{Characteristic Features of Public Health as Basic Conditions for Inquiry-Based Learning}

\subsubsection{Public Health as a Scientific discipline}

Public Health as "Holistic" Alternative to Medical Studies The field of public health has developed in Germany since the 1980s, with increased development in the 1990s, in conjunction with efforts to create an academic quality initiative in the healthcare system, which bundles a broad spectrum of healthcare occupations having differing qualification levels, educational institutions and professional settings. Public health prefers to consider health and healthcare holistically, critically reflect and limit the power of interpretation of medicine in the health sector, and develop other perspectives. Thus public health has offered, and continues to offer, a significant complement to traditional medical studies, a new perspective on continuing education and the career paths for physicians in Germany associated therewith (Polak 1999; von Troschke 2002). Initially designed as a course of study to be pursued part-time alongside employment, public health quickly developed into a degree program with various opportunities for specialization, which also signaled the academization and professionalization of healthcare occupations, for example physical therapy or speech therapy (Blättner 2012). Development away from a "vertical, hierarchical professional structure" is also being supported (Immenroth 2012, p. 57, translated).

Public Health as a Multidiscipline with a Transdisciplinary Orientation Public health involves a range of different core subjects, which represent different disciplines of science and their perspective on the common subject; the health of the population. These include: epidemiology, statistics/methods, medical basics, social and behavioral science basics, health promotion and prevention, health economics, healthcare policy, healthcare management, work, environment and health, law and ethics and research into the healthcare system (Dierks 2012). In addition, scientific aspects of nursing practice and theory were integrated such as nursing science, nursing education and nursing management (von Troschke 1999). Public health/health sciences are characterized by a transdisciplinary approach to health policy and practice or, respectively, to the transfer of knowledge to healthcare practice. Combining the various foci provides those who will be employed in the healthcare system in the future with a basis for the core competencies, for example competency in interprofessional cooperation. For example, these competencies have been documented in the Careum paper (Sottas et al. 2013), a position paper on reforming the training of health professionals in the twenty-first century, which emphasizes networking between those who will be working in the healthcare sector in the future.

Public Health as Applied Science Public health is an applied science. A mandate that emphasizes the connection between science and healthcare can be seen as early as Winslow's definition of public health (Winslow 2001), which was formulated in 1920 and adopted by the WHO in 1953 (Polak 1999). According to Noack (1999), the goals are to control and regulate health systems, to create basic social conditions for health, and to maintain and promote the social and organizational conditions for health. Dierks (2012) 
specifies that the goal of public health is in educating professionals in planning and decision-making in the healthcare system, and in developing, implementing and evaluating health-promoting and preventive programs, and likewise in founding health research and teaching. A clear definition of the field is lacking, however, which makes it difficult to distinguish between the different study orientations and the comparability of degrees (Dierks 2012). To date, problems associated with the application orientation such as the handling of different professional and disciplinary communication and process cultures have scarcely been systematically addressed (Schröder-Bäck 2014). Additional challenges include dealing with the pitfalls associated with labor law in transdisciplinary commissioned research and the need for a specific research ethics relating to public health, as well as the lack of epistemological considerations on the epistemology and methodology of the subject (ibid.).

The Heterogeneity of Students and Instructors The wide range of occupations and scientific disciplines that deal with health and the different paths to qualification substantiate the heterogeneity of both instructors and students in the public health. Thus, according to the Bremen student survey QUEST (2010/2012), a majority of new students have completed vocational training, work experience or experience through social engagement (Universität Bremen 2014). They are therefore older and more experienced than students in other disciplines. Moreover, the QUEST analysis further characterized this student group as pragmatic and dutiful - and less theoretical. Political involvement, artisticcultural activities or experiences abroad are less common in the public health group as compared with students in other departments (ibid.). In addition, it is largely female students who are interested in the field. The percentage of women is over 80 percent (ibid.). To date, however, there is still a lack of reflection on gender and diversity within the subject culture and by the healthcare professions. The instructors are also characterized by heterogeneity. The majority of instructors recently came from independent scientific disciplines such as medicine, biology, economics or sociology and, as a rule, were qualified through a continuing education degree program or by working on health-related issues in their field of origin. The field has been changing since the first graduates of undergraduate degree programs in the field first took academic positions.

\subsubsection{Didactics in Public Health}

The plural disciplinary constitution, the adaptations due to the Bologna Process and the applied approach need not be an argument for strongly regulated B.A. and M.A. instruction. The exclusive concentration on a transfer of knowledge that focuses entirely on subject-specific knowledge also reaches its limits if students are to be enabled to establish interdisciplinary and transdisciplinary connections between theory and practice (Völker 2004).

The desire for greater interdisciplinary alignment, discussions about a common methodology and theory of cognition, a sense of history, and options in dealing with theorypractice problems in the case of commissioned research can foster the development of 
innovative didactic models for holistic teaching and learning. Projects such as that of the "Kooperationsverbund Hochschulen für Gesundheit" (Cooperation Network of Universities for Health) comment on the guiding didactic principles, which are supposed to ensure that students have essentially comparable qualifications (Hochschulen für Gesundheit e.V. 2001). The Deutsche Gesellschaft für Hochschuldidaktik (German Society for University Didactics) also has a health science working group focusing on the subject. A systematic didactical reflection with regard to the above-mentioned challenges is the exception, however. This is made apparent by the small number of publications on the topic (Reiber 2012a). According to Reiber, insofar as it occurs at all in health science instruction, this reflection is made in reference to literature and findings from general higher education didactics (ibid.).

The multi- and transdisciplinary references and the explicit call for the applicability of the contents, as well as the heterogeneity of the teachers and students, could make the inquiry-based learning approach (cf. Mieg in this volume) interesting in public health. Inquiry-based learning could provide instruments that move the discipline away from the multiplicity of perspectives represented by the individual disciplines towards theoretically and methodologically based inter- and transdisciplinarity, thereby connecting both students and instructors with one another. Van Wickevoort Crommelin (n.d.) summarizes the following points as shared characteristics of inquiry-based learning approaches as follows:

1. The problem and question, as well as the methods of answering, are self-chosen and possibly self-developed, and are reflected upon in an exchange with others (students, instructors, the public).

2. The procedures are based on scientific principles, and the research process and the results are critically reviewed.

3. Interdisciplinarity will be considered and the findings will be presented to a (professional) public, for example the student body or practice partners.

Whether and the degree to which inquiry-based learning offers solutions here will be examined below.

\subsubsection{Inquiry-Based Learning in Public Health}

Learning arrangements that are intended to promote interdisciplinary development in public health include "Regional Health Universities," for example (Sottas et al. 2013). This didactic approach was pursued in the 1970s and aimed to strengthen the integrated training of health professionals across professional boundaries and care sectors (ibid.). However, this will not build a bridge to inquiry-based learning. Reiber explicitly addresses 
the benefit to the public health sciences associated with inquiry-based learning (Reiber 2012a, 2012b). She sees potential for multidisciplinary reflexivity in education, for example: Research results from differently designed studies could be received in a multiperspectivist and critical manner using inquiry-based learning, and different research paradigms could be discovered. This would thereby make it possible to grasp the applied approach of the field through research activity and thus foster students' understanding of public health and professional self-understanding. Likewise, it would be possible to develop the ethically based power of judgment needed in the profession (Schröder-Bäck 2014). Inquiry-based learning could thus help involved practice partners to understand which competencies students could bring to the professional practice.

To our knowledge, there has been no systematic review to date of inquiry-based learning in public health. The implementation of inquiry-based learning in public health and the design of public health studies seem to be situated in the curriculum at individual institutions of higher learning. One example of embedding inquiry-based learning in the public health can be found at the institute for educational and health-care research in the health sector (InBVG) at the Bielefeld University of Applied Sciences (Weyland and Nauerth 2013). Here, the entire course of studies in teacher education for the healthcare occupations includes inquiry-based learning. It is integrated in both the master's and bachelor's degree programs and includes both small-scale research as well as multi-semester projects (ibid.).

Another example is the "FLexeBel - Forschendes Lernen zur Vorbereitung auf komplexe und interdisziplinäre Berufsfelder” ("FLexeBel - inquiry-based learning in preparation for complex and interdisciplinary professional fields") project at the University of Bremen. It is aimed at the implementation of inquiry-based learning in all teaching modules of the master's degree program in "healthcare provision, health economics and healthcare management" (FLexeBel 2015) ["Gesundheitsversorgung, -ökonomie und -management"]. The bachelor's degree program at the University of Bremen also includes inquiry-based learning. The seminar on occupational health management in "daycare centers" settings, which was financially supported, designed and carried out within the context of the ForstA project (research-based study right from the start) was exemplary. The goal was to implement occupational health management in daycare centers using inquirybased learning. Over the course of two semesters,

1. theoretical fundamentals regarding occupational health management were taught,

2. practiced using virtual examples and

3. applied to the actual situation in daycare centers.

The measures for introducing inquiry-based learning into public health sciences are part of the overall strategy for the implementation of inquiry-based learning at the University of Bremen (cf. Kaufmann \& Schelhowe, in this volume). 


\subsection{Critical Discussion and Outlook for the Field of Public Health}

As a didactic concept, how can inquiry-based learning help address the specific challenges faced by public health (e.g. the holistic theoretical/practical relevance and the difficult integration of multidisciplinary perspectives)? In the following, we highlight some points that go beyond purely programmatic requirements and should be discussed in public health in order to pave the way for innovative didactic concepts such as inquiry-based learning. This includes sufficient reception and elaboration of the concept of inquiry-based learning for public health didactics, for example. This will make more orientation options available to public health instructors for planning their teaching projects - in a very practical way on the one hand, and in epistemological engagement with their own subject on the other. Both aspects will be examined below, whereby they are, in part, relevant to the approach to inquiry-based learning beyond public health as well.

On the practical side, for example, inquiry-based learning emphasizes an equal learning alliance in which students are guided through the research process in the sheltered environment of a seminar. Associated changes in role expectations and demands on the organization of the lesson design in terms of time and content can create confusion and should not be left unexamined. In the example of implementing health management in daycare centers, the more flexible organization in the inquiry-based learning setting met students' needs. Small group work made it possible to organize working hours flexibly and individually outside of a fixed lecture schedule. Students with part-time jobs or responsibility for schooling or care particularly appreciated the benefits. Here, the process-oriented setting of inquiry-based learning countered the heterogeneity of the students.

The more flexible and group-specific learning settings also created difficulties, however, which indicate that innovative teaching formats such as inquiry-based learning in public health should already be taken into consideration when planning curriculum for B.A. and M.A. studies. Examples include clashes with established, administrative structures and work regulations - whether these be examination rules, role expectations in a hierarchical teaching/learning system that is focused on grading, time constraints, forms of collaboration, and so on. This may thus be associated with additional work for both instructors and learners that should not be underestimated in order to ensure that activities are timely and conform with administrative expectations (e.g. by means of exception rules).

In addition to questions concerning the concrete design of teaching and learning settings, it is generally necessary to consider how the concept of inquiry-based learning can be designed constructively under the conditions of multidisciplinary public health and possibly even lead to interdisciplinary teaching and learning. For us, the key to this lies in reflection during the research and learning process. According to Huber, these should include three levels of reflection according to the humanistic cognitive ideal: "the selfreflection of scholarship as a mode of rational cognition, the self-reflection of the subject 
through scholarship, and the reflection on the common good to be promoted thereby" (2009, p. 3 et seq.; for details, see also Huber, in this volume).

The first two levels of reflection are still in their infancy in the science culture of public health: The cognitive tools used by public health come from other disciplines. They are shaped by different scientific cultures and tend to stand side by side. As yet, there has been no systematic reflection on the understanding of science with regard to public health, the situatedness of the knowledge and the researchers, as well as the ethical responsibilities of the health professionals and those conducting research in the health sector. Inquiry-based learning could introduce well-founded reflection into the learning setting, thereby also supporting instructors who may also lack the theoretical and analytical foundations of the different core disciplines. Without reflection on the understanding of science and research as the basis for the research process, this could lead to more research-oriented learning, as in the daycare example. This leaves the applicability of the research and public health understanding of itself, as well as the homogeneity of the students as researchers and professionals in the field of health policy, unexamined.

Another item from discussions regarding inquiry-based learning in public health sciences concerns the relevance of the findings for third parties, i.e. for scientific contexts as well as for practice partners (cf. Huber 2009). The "third party" is first and foremost the scientific community: the seminar group, the department or a scientific forum. Here, Huber (2009) refers to requirements that can also be met by student work within the students' abilities, and not to trailblazing research innovations that alter a scientific community. This pertains to requirements that do not call into question the contents of the everyday scientific work of teachers and scientific staff (cf. ibid.). According to Tremp (2014), the students are the main addressees of the presentation of results. Critical aspects of the orientation towards third parties emerge, for example, when the relevance of the topic for practical partners fails to coincide with the scientific relevance of a topic, such as when the goals of applicability and commissioned research and the goals of scientific insight diverge. Both areas of relevance should be critically and explicitly reflected upon in relation to the research and learning process in the seminar, however. This constant work of reflection must not fall prey to the elaborate organization of time and activity in the process of inquiry-based learning in public health.

And what happens if the "third parties" are healthcare enterprises or charities that want to continue working with the seminar results and do not focus on the research and learning process? The third parties being addressed are thus primarily students' potential employers. Mutual expectations will be exaggerated, clients will expect economically beneficial results and students will be less concerned with the learning process of scientific reflection than with output, which is to say with the effort to deliver a "product." In addition, concentration on the "product" places the process-critical reflection of the students" approach and the assessment of their scientific work at risk. 
A problem with which inquiry-based learning settings could be confronted is shown in the example of corporate inquiries that seek to implement inquiry-based learning in certain health-related corporate contexts. This is an aspect that is initially positive, as it speaks to the positive external perception of degree programs in the health sciences and provides students with an option to acquire practical occupational experience without interrupting their studies. What is vexing about these requests, however, is the content and scope of the services requested. Examples include coordinating and carrying out a national representative survey for quality assurance or the call for tenders for a complete evaluation of outpatient healthcare activities. From a student perspective, this creates a kind of internship construct which, in the best-case scenario, makes it possible for the student to join the company upon graduation and, in the worst-case scenario, must be presented as a "failed project" in the seminar. Here, companies bear neither (personnel or material) costs (e.g. for the data collection, transcriptions or travel) nor risks. From the beginning, it should therefore be very clearly agreed with the practice partner that in the case of inquiry-based learning, what is at stake is the research and learning process in the sheltered environment of the university, and not added economic value. If this discussion is not held, questions will remain as to the degree to which self-exploitation is being promoted as part of the university's organizational and value culture, especially in applied disciplines such as health sciences, by providing services without an economic quid pro quo. In developed professions, for example in the planning field (architecture, civil engineering), professional associations and organizations frequently prohibit institutions of higher learning from undertaking low-cost projects that could also be carried out by professional planning offices; see, for example, the fee structure imposed on architects and engineers acting as public contractors (HOAI). As a multidiscipline, public health still needs to find its own way in this regard.

In summary, it should be said that, as an innovative, didactic concept in public health, inquiry-based learning requires conducive disciplinary conditions pertaining to the structure of higher education if it is to develop good, reflective research and a self-reflective research attitude, as well as multi- and transdisciplinary collaboration. In public, if desired and implemented well, it can initiate sustainable sensitization and qualification processes for both young scientists and instructors as well, in order to meet the challenges of the young discipline.

\section{References}

Blättner, B. (2012). Public Health-Inhalte in anderen gesundheitswissenschaftlichen Studiengängen. In F. W. Schwartz/U. Walter/J. Siegrist/P. Kolip/R. Leidl/M. L. Dierks/R. Busse/N. Schneider (Hrsg.), Public Health. Gesundheit und Gesundheitswesen (S. 807-810). München: Urban \& Fischer.

DGPH (2015). Was ist Public Health? Retrieved 29 October 2015 from http://www.deutsche-gesellschaft-public-health.de/informationen/public-health 
Dierks, M.-L. (2012). Public-Health-Ausbildung in Deutschland und Berufsfelder der Absolventinnen und Absolventen. In F. W. Schwartz/U. Walter/J. Siegrist/P. Kolip/R. Leidl/ M. L. Dierks/R. Busse/N. Schneider (Hrsg.), Public Health. Gesundheit und Gesundheitswesen (S. 799-804). München: Urban \& Fischer.

FLexeBel (2015). Forschendes Lernen zur Vorbereitung auf komplexe und interdisziplinäre Berufsfelder (FLexeBel). Retrieved 29 October 2015 from http://www.ipp.uni-bremen.de/ forschung/abteilung-1\%2D\%2Dversorgungsforschung/projekte/?proj=633

Hochschulen für Gesundheit e.V. (2001). Leitbilder für das Projekt Multimedialer Kooperationsverbund: Hochschulen für Gesundheit. Retrieved 29 October 2015 from http:// blog.hochges.de/wp-content/uploads/2013/04/leitbilder_hochschulen-fuer-gesundheit.pdf

Huber, L. (2009). Warum Forschendes Lernen nötig und möglich ist. In L. Huber/J. Hellmer/ F. Schneider (Hrsg.), Forschendes Lernen im Studium (S. 9-35). Bielefeld: Universitäts VerlagWebler.

Immenroth, T. (2012). Employability als Ziel dualer Pflegestudiengänge. In $A$. Nauerth/U. Walkenhorst/R. von der Heyden (Hrsg.), Hochschuldidaktik in pflegerischen und therapeutischen Studiengängen (S. 57-74). Berlin: Lit Verlag Dr. W. Hopf.

Noack, H. R. (1999). Public Health an der Schwelle zum 21. Jahrhundert: Tradition, Modernisierung, Herausforderung und Vision. In G. Polak (Hrsg.), Das Handbuch Public Health. Theorie und Praxis. Die wichtigsten Public-Health-Ausbildungsstätten (S. 8-36). Wien u. a.: Springer.

Polak, G. (1999). Das Handbuch Public Health: Theorie und Praxis. Die wichtigsten Public-HealthAusbildungsstätten. Wien u. a.: Springer.

Reiber, K. (2012a). Hochschuldidaktik für gesundheitsbezogene Studiengänge. Eine theoretische Grundlegung. In R. Richter/C. Baatz (Hrsg.),Tübinger Beiträge zur Hochschuldidaktik, 8(2012), Retrieved 29 Octiber 2015 from https://publikationen.uni-tuebingen.de/xmlui/ handle/10900/43953

Reiber, K. (2012b). Kompetenzentwicklung durch forschendes Lernen in pflege- und gesundheitsbezogenen Studiengängen. In A. Nauerth/U. Walkenhorst/R. von der Heyden (Hrsg.), Hochschuldidaktik in pflegerischen und therapeutischen Studiengängen (S. 17-28). Berlin: Lit Verlag Dr. W. Hopf.

Schröder-Bäck, P. (2014). Ethische Prinzipien für die Public-Health-Praxis: Grundlagen und Anwendungen. Frankfurt/New York: Campus Verlag.

Sottas, B./Höppner, H./Kickbusch, I./Pelikan, J./Probst, J. (2013). Educating Health Professionals: $n$ Intersectoral Policy Approach (careum working paper 7). Zürich: Careum Stiftung.

Tremp, P. (2014). Forschendes Lernen als Profilmerkmal einer Universität: Kommentierung der Beispiele aus der Universität Bremen und Fragen an das Lehrprofil. Retrieved 18 April 2015 from http://www.uni-bremen.de/fileadmin/user_upload/single_sites/qm/Hochschuldidaktik/ Bremen_Lehrprofil_Bericht_TREMP.pdf

Universität Bremen (2014). Studierendenbefragung QUEST. Retrieved 29 October 2015 from http:// www.uni-bremen.de/de/quest.html

Van Wickevoort Crommelin, A. (o.D). Forschendes Lernen - Genese, Ansätze und geeignete Formate. Retrieved 18 April 2015 from http://www.uni-greifswald.de/fileadmin/mp/1_studieren/ Qualitaetssicherung/interStudies/Forschendes-Lernen_Genese-Ansaetze-Formate.pdf

Völker, H. (2004). Von der Interdisziplinarität zur Transdisziplinarität? In F. Brand/F. Schaller/ H. Völker (Hrsg.), Transdisziplinarität: Bestandsaufnahme und Perspektiven (S. 9-28). Göttingen: Universitätsverlag Göttingen.

Von Troschke, J. (1999). Public Health in Deutschland. Aus- Fort- und Weiterbildung in den Gesundheitswissenschaften. In G. Polak (Hrsg.), Das Handbuch Public Health. Theorie und Praxis. Die wichtigsten Public-Health-Ausbildungsstätten (S. 205-216). Wien u. a.: Springer. 
Von Troschke, J. (2002). Geschichte und Entwicklung von Gesundheitswissenschaften und Public Health in Deutschland. Public Health Forum, 10(3), 4-5.

Weyland, U./Nauerth, A. (2013). Forschendes Lernen in der Lehrerbildung für Gesundheitsberufe [Poster]. Fachhochschule Bielefeld.

Winslow CEA (2001). Winslow's definition of public health. In Encyclopedia Britannica (S. 740). Vol. 15. London, England: Encyclopedia Britannica Inc. [cf. Winslow CEA (1920). The unfilled field of public health. Modern Medicine 2, 183-191.]

Open Access This chapter is licensed under the terms of the Creative Commons AttributionNonCommercial-NoDerivatives 4.0 International License (http://creativecommons.org/licenses/bync-nd/4.0/), which permits any noncommercial use, sharing, distribution and reproduction in any medium or format, as long as you give appropriate credit to the original author(s) and the source, provide a link to the Creative Commons licence and indicate if you modified the licensed material. You do not have permission under this license to share adapted material derived from this chapter or parts of it.

The images or other third party material in this chapter are included in the chapter's Creative Commons licence, unless indicated otherwise in a credit line to the material. If material is not included in the chapter's Creative Commons licence and your intended use is not permitted by statutory regulation or exceeds the permitted use, you will need to obtain permission directly from the copyright holder.

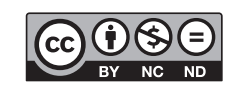

